\title{
JURNAL AUDI
}

Jurnal Ilmiah Kajian Ilmu Anak dan Media Informasi PAUD

http://ejurnal.unisri.ac.id/index.php/jpaud/article/view/3029

\section{PENINGKATAN PERKEMBANGAN KOGNITIF ANAK MELALUI} PENDEKATAN SAINTIFIK PADA ANAK KELOMPOK B

\author{
Eni Rahayu ${ }^{1}$, Hera Heru Suryanti ${ }^{2}$, M. Hery Yuli Setiawan ${ }^{3}$ \\ PG_PAUD Universitas Slamet Riyadi Surakarta
}

\section{Info Artikel}

Sejarah Artikel:

Diterima April 2019

Disetujui Mei 2019

Dipublikasikan Juni 2019

\section{Keywords:}

Scientific Approach,

Cognitive Development, Early Childhood

\begin{abstract}
Abstrak
Tujuan penelitian ini adalah mengetahui peningkatan perkembangan kognitif pada anak melalui pendekatan saintifik di kelompok B TK Pertiwi II Gagaksipat Boyolali Tahun Pelajaran 2018/2019.Penelitian ini dilaksanakan di TK Pertiwi II Gagaksipat Boyolali. Subjek dalam penelitian ini adalah siswa kelompok B yang berjumlah 24 siswa. Penelitian ini adalah Penelitian Tindakan Kelas (PTK) yang dilaksanakan dalam 2 siklus, setiap siklus terdiri dari 4 tahap yaitu, perencanaan, tindakan, observasi dan refleksi. Teknik analisis data yang digunakan adalah deskriptif kuantitatif yaitu dengan mendeskribsikan kegiatan kemudian membandingkan nilai hasil belajar kondisi awal, siklus I, dan siklus II. Teknik pengumpulan data dengan observasi, wawancara, dan dokumentasi. Hasil penelitian menunjukkan bahwa pendekatan saintifik dapat meningkatkan perkembangan kognitif anak kelompok B TK Pertiwi II Gagaksipat Boyolali. Pada siklus I perkembangan kognitif anak mengalami peningkatan sebesar $50 \%$. Sedangkan dalam siklus II, perkembangan kognitif anak mengalami peningkatan sebesar $79,16 \%$. Berdasarkan penelitian tersebut dapat diambil kesimpulan bahwa penerapan pendekatan saintifik dapat meningkatkan perkembangan kognitif pada anak kelompok B.
\end{abstract}

\begin{abstract}
The aim of this research is to find out the improvement of cognitive development in children through a scientific approach in group B of TK Pertiwi II Gagaksipat Boyolali in 2018/2019 academic year. This research was conducted in TK Pertiwi II Gagaksipat Boyolali. The research subject was students in group B with the total number of students were 24 students. This research was a Classroom Action Research (CAR) which was held in 2 cycles. Every cycle consisted of 4 steps, they were planning, acting, observing, and reflecting. The technique of data analysis used descriptive qualitative. It described the activities and then compared the final scores of learning achievement in the precondition, cycle I and cycle II. The technique of data collecting was observation, interview, and documentation. Research result showed that a scientific approach could improve the cognitive development of children in group B, TK Pertiwi II Gagaksipat Boyolali. In the cycle, the cognitive development of children has increased by $50 \%$. While in cycle II, children's cognitive development has increased by $79,16 \%$. Based on this research, it could be concluded that the implementation of a scientific approach can improve the cognitive development of children in group B.
\end{abstract}

(C) 2019 FKIP Universitas Slamet Riyadi 


\section{PENDAHULUAN}

Pendidikan Anak Usia Dini (PAUD) adalah pendidikan yang diselenggarakan dengan tujuan untuk memfasilitasi pertumbuhan dan perkembangan anak secara menyeluruh atau menekankan pada pengembangan seluruh aspek perkembangan anak. (Muhiyatul, 2016: 62). Senada dengan pendapat Kristanto, dkk (2011:49) yang menyatakan "Pendidikan Anak Usia Dini (PAUD) adalah suatu proses pembinaan tumbuh kembang anak usia lahir hingga enam tahun secara menyeluruh, yang mencakup aspek fisik dan non fisik dengan memberikan rangsangan bagi perkembangan jasmani, rohani (moral dan spiritual), motorik, akal fikir, emosional, dan sosial yang tepat dan benar agar anak tumbuh dan berkembang secara optimal. Adapun upaya yang dilakukan mencakup stimulasi intelektual, pemeliharaan kesehatan, pemberian nutrisi, dan penyediaan kesempatankesempatan yang luas untuk mengeksplorasi dan belajar secara aktif". Pendidikan Anak Usia dini merupakan fundamen yang sangat diperlukan agar anak siap memasuki tahapan perkembangan maupun pendidikan selanjutnya. Tujuan PAUD ada dua, yaitu tujuan utama dan tujuan penyerta. Tujuan utama adalah membentuk anak Indonesia yang berkualitas, yaitu anak yang tumbuh dan berkembang sesuai tingkat perkembangannya sehingga memiliki kesiapan yang optimal di dalam memasuki pendidikan dasar serta mengarungi kehidupan di masa dewasa. Sedangkan tujuan penyerta yaitu membantu menyiapkan anak mencapai kesiapan belajar di sekolah.

Anak usia dini adalah anak yang sedang membutuhkan upaya pendidikan untuk mencapai optimalisasi semua aspek perkembangan, baik perkembangan fisik maupun psikis yang meliputi perkembangan nilai-nilai agama dan moral, kognitif, bahasa, motorik, seni dan sosial emosional. Permendikbud No. 137 tahun 2014 terdapat lima aspek pengembangan yang harus diterapkan dalam setiap pelaksanaan pendidikan anak usia dini, yaitu: nilai agama dan moral, sosial emosional, bahasa, kognitif dan fisik motorik. Dalam setiap aspek terdapat indikator yang memudahkan para pendidik untuk mengembangkan kegiatan yang menarik bagi anak. Setiap aspek memiliki komponen yang harus dikembangkan sesuai dengan indikator yang ada. Salah satu dari aspek di atas adalah aspek perkembangan kognitif.

Kemampuan kognitif sangat penting dikembangkan sedini mungkin. Anak memiliki rasa ingin tahu yang tinggi terhadap benda yang ada di sekitarnya. Sehingga anak berusaha mencari tahu apa yang mereka lihat dan apa yang mereka ketahui dengan memberikan pembuktian dan berusaha menyimpulkan. Dalam pemberian rangsangan pada aspek perkembangan kognitif maka peran guru, orang tua dan orang dewasa sangat penting. Pemberian rangsangan pada anak usia dini perlu disesuaikan dengan karakteristik perkembangannya, yaitu melalui bermain. Oleh karena itu dibutuhkan pendekatan saintifik bagi anak dalam proses pembelajaran.

Pembelajaran saintifik penting di terapkan disetiap jenjang pendidikan untuk memberikan suatu pengenalan konsep kehidupan sehari- hari. Sains juga melatih anak menggunakan lima inderanya untuk mengenal berbagai gejala benda dan peristiwa. Proses pembelajaran saintifik untuk anak usia dini (PAUD) dilakukan melalui kegiatan belajar sambil bermain. 
Melalui kegiatan bermain, anak mampu mengeksplorasi pengetahuannya dan mampu merangsang anak untuk berpikir memecahkan masalah. Pembelajaran saintifik juga termasuk dalam aspek kognitif. Dalam aspek kognitif anak di harapkan mampu mengenal konsep yang berhubungan dengan pemahaman dan pengetahuan. Bidang kognitif dibagi menjadi tiga bidang yaitu bidang pengetahuan umum, sains, konsep bentuk, warna, dan ukuran, konsep bilangan, lambang bilangan dan huruf. Proses pembelajaran saintifik juga dapat diterapkan melalui suatu pendekatan ilmiah. Menurut Ditjen PAUDNI Pendekatan saintifik merupakan suatu pendekatan ilmiah, dirancang sedemikian rupa agar anak secara aktif mengkontruk kompetensi sikap, pengetahuan, dan keterampilan melalui tahapan mengamati, menanya, mengumpulkan informasi, menalar dan mengkomunikasikan . Pendekatan saintifik tidak diartikan sebagai belajar sains tetapi menggunakan proses saintifik dalam kegiatan belajar. Mengacu pada kurikulum terbaru yaitu kurikulum 2013, proses pembelajaran di setiap jenjang pendidikan dilaksanakan secara tematik integratif. Selain itu kurikulum 2013 mencanangkan adanya suatu pendekatan, yaitu pendekatan saintifik (scientific approach) dalam proses pembelajaran. Pendekatan dengan menggunakan cara ilmiah dalam menghadapi suatu masalah.

Dengan pendekatan saintifik diharapkan mampu mempersiapkan generasi yang berpikir kritis dan berketerampilan. Hal ini sesuai dengan perubahan paradigma pembelajaran dari teacher center menjadi students center. Pembelajaran tidak lagi berpusat kepada guru, melainkan kepada anak didik. Anak didik tidak lagi dianggap sebagai selembar kertas putih ataupu gelas kosong. Peranan guru yaitu merancang pembelajaran, mengenali tingkat pengetahuan individu anak didik dan memotivasi peserta didik untuk meningkatkan keberhasilan anak didik dan menyiapkan kondisi belajar yang menyenangkan. Oleh karena itu pendidik dituntut lebih kreatif.

Pembelajaran saintifik penting diterapkan disetiap jenjang pendidikan untuk memberikan suatu pengenalan konsep kehidupan sehari-hari. Proses pembelajaran saintifik untuk anak usia dini (PAUD) dilakukan melalui kegiatan belajar sambil bermain. Menurut A. Machin (2014: 28) Mengatakan " Pembelajaran melalui pendekatan saintifik adalah proses pembelajaran yang dirancang sedemikian rupa agar peserta didik secara aktif mengonstruksi konsep, hukum atau prinsip melalui tahapan-tahapan mengamati (untuk mengidentifikasi atau menemukan masalah), merumuskan masalah, mengajukan atau merumuskan hipotesis, mengumpulkan data dengan berbagai teknik, menganalisis data, menarik kesimpulan dan mengomunikasikan konsep, hukum atau prinsip yang ditemukan". Menurut Asep S. (2011:216) "Seseorang anak dikatakan menguasai sains dari dimensi proses, apabila cara kerja dia dalam mengenal, menggali dan mengungkap segala sesuatu yang terkait dengan alam ini serta segala permasalahannya, mengikuti proses ilmiah dengan kata lain menggunakan metode ilmiah (scientific method)".

\section{KAJIAN PUSTAKA}

Piaget dalam Fatimah I (2015:29) "menjelaskan bahwa dia lebih menitik beratkan pembahasannya pada struktur kognitif. Ia meneliti dan menulis subjek perkembangan kognitif ini dari tahun 1927 sampai 1980. Berbeda dengan para ahli-ahli psikologi sebelumnya. Ia menyatakan bahwa cara berfikir anak 
bukan hanya kurang matang dibandingkan dengan orang dewasa karena kalah pengetahuan, tetapi juga berbeda secara kualitatif". Menurut Reny D,(2013: 2) "Untuk mengembangkan kemampuan kognitif pada anak, guru harus melakukan kegiatan yang menarik bagi anak, menciptakan situasi pendidikan yang dapat memberikan rasa aman dan nyaman, menggunakan strategi, metode, materi/bahan, media yang menarik dan mudah diikuti oleh anak serta memberikan motivasi agar anak mampu berpikir dengan baik. Sehingga anak mempunyai kesempatan yang sangat besar untuk berkembang". Menurut Bloom dalam Gunawan dan Anggraini R (2012:100) mengatakan "Taksonomi Bloom mengklasifikasikan perilaku menjadi enam kategori, dari yang sederhana (mengetahui) sampai dengan yang lebih kompleks (mengevaluasi). Ranah kognitif terdiri atas (berturut-turut dari yang paling sederhana sampai yang paling kompleks)",.

Pendekatan saintifik menurut (Daryanto, 2014:51) adalah proses pembelajaran yang dirancang agar anak dapat secara aktif mengontruksi konsep, hukum, atau prinsip melalui tahap mengamati, merumuskan masalah, mengajukan dan merumuskan hipotesis, mengumpulkan data dengan berbagai teknik, menganalisis data, menarik kesimpulan, dan mengkomunikasikan konsep, hukum atau prinsip yang ditemukan.

\section{METODE}

Penelitian ini dilaksanakan di TK Pertiwi II Gagaksipat Boyolali pada tahun pelajaran 2018/2019. Penelitian dilaksanakan pada semester Gasal/Genap selama 6 bulan, yaitu pada bulan Mei s.d. Oktober 2018 sejak penyusunan proposal pada tahun pelajaran 2018/2019. Subjek dalam penelitian ini adalah anak kelompok B TK Pertiwi II Gagaksipat Boyolali tahun pelajaran 2018/2019, yang berjumlah 24 anak. Jumlah tersebut terdiri dari 14 anak perempuan dan 10 anak laki-laki.

Model penelitian ini merupakan penelitian tindakan kelas, karena penelitian dilakukan sesuai dengan langkah-langkah pada penelitian tindakan kelas yang meliputi penyusunan rencana, melaksanakan tindakan, mengobservasi, melakukan analisis dan refleksi terhadap hasil observasi dari hasil analisis dan refleksi setiap akhir kegiatan dilakukan tindakan perbaikan terhadap siklus yang selanjutnya berdasarkan analisis dan refleksi yang dibuat sebelumnya. Menurut Suharsimi Arikunto (2009:117) pada prosedur penelitian ini menggunakan langkah-langkah penelitian tindakan kelas model siklus dikarenakan objek penelitian yang diteliti hanya satu sekolah. Teknik pengumpulan data dengan menggunakan observasi, wawancara, dan dokumentasi. Validitas data adalah triangulasi yaitu teknik pemeriksaan keabsahan data yang memanfaatkan sesuatu yang lain diluar data untuk keperluan pengecekan atau sebagai pembanding. 
HASIL

Diskripsi Kondisi Awal

Tabel. 1 Rekapitulasi Data Hasil Observasi Pra Siklus

\begin{tabular}{lcc}
\hline \multicolumn{1}{c}{ Kriteria } & $\begin{array}{c}\text { Jumlah } \\
\text { Siswa }\end{array}$ & Presentase \\
\hline $\begin{array}{l}\text { Perkembangan Kognitif } \\
\text { Berkembang Sangat Baik }\end{array}$ & - & - \\
Perkembangan Kognitif & 3 & $12,50 \%$ \\
$\begin{array}{l}\text { Berkembang Sesuai } \\
\text { Harapan }\end{array}$ & & \\
$\begin{array}{l}\text { Perkembangan Kognitif } \\
\text { Mulai Berkembang }\end{array}$ & 14 & $58,33 \%$ \\
$\begin{array}{l}\text { Perkembangan Kognitif } \\
\text { Belum Berkembang }\end{array}$ & 7 & $29,16 \%$ \\
& & \\
\hline
\end{tabular}

Dari tabel diatas dapat diketahui bahwa tingkat perkembangan kognitif anak masih masih belum berkembang sebanyak 7 siswa yaitu dengan presentase sebesar 29,16\%. Anak dengan kriteria mulai berkembang sebanyak 14 siswa yaitu dengan presentase sebesar 58,33\%. Anak dengan kriteria berkembang sesuai harapan sebanyak 3 siswa dengan presentase sebesar $12,50 \%$. Menurut rekapitulasi data diatas, perolehan ratarata diatas belum mencapai indikator keberhasilan yang diinginkan yaitu dengan kriteria berkembang sangat baik dan presentase $\geq 75 \%$.

\section{Diskripsi Siklus 1}

Tabel. 2 Rekapitulasi Data Hasil Observasi Siklus I

\begin{tabular}{|c|c|c|c|c|}
\hline \multirow[t]{2}{*}{ Kriteria } & \multicolumn{2}{|c|}{ Pertemuan 1} & \multicolumn{2}{|c|}{ Pertemuan 2} \\
\hline & $\begin{array}{l}\text { Juml } \\
\text { ah } \\
\text { Sisw } \\
\text { a }\end{array}$ & $\begin{array}{l}\text { Prese } \\
\text { ntase }\end{array}$ & $\begin{array}{l}\text { Juml } \\
\text { ah } \\
\text { Sisw } \\
\text { a } \\
\end{array}$ & $\begin{array}{l}\text { Prese } \\
\text { ntase }\end{array}$ \\
\hline $\begin{array}{l}\text { Perkembangan } \\
\text { Kognitif } \\
\text { Berkembang Sangat } \\
\text { Baik }\end{array}$ & 1 & $\begin{array}{c}4,16 \\
\%\end{array}$ & 3 & $\begin{array}{c}12,5 \\
0 \%\end{array}$ \\
\hline $\begin{array}{l}\text { Perkembangan } \\
\text { Kognitif } \\
\text { Berkembang Sesuai } \\
\text { Harapan }\end{array}$ & 8 & $\begin{array}{c}33,3 \\
3 \%\end{array}$ & 9 & $\begin{array}{c}37,5 \\
0 \%\end{array}$ \\
\hline $\begin{array}{l}\text { Perkembangan } \\
\text { Kognitif Mulai } \\
\text { Berkembang }\end{array}$ & 12 & $\begin{array}{c}50,0 \\
0 \%\end{array}$ & 12 & $\begin{array}{c}50,0 \\
0 \%\end{array}$ \\
\hline $\begin{array}{l}\text { Perkembangan } \\
\text { Kognitif Belum } \\
\text { Berkembang }\end{array}$ & 3 & $\begin{array}{l}12,5 \\
0 \%\end{array}$ & - & - \\
\hline
\end{tabular}

Melihat data dari tabel diatas dapat diketahui bahwa tingkat perkembangan kognitif anak dengan kriteria mulai berkembang sebanyak 12 siswa yaitu dengan presentasesebesar 50,00\%. Anak dengan kriteria berkembang sesuai harapan meningkat sebanyak 9 siswa dengan presentase sebesar 37,50\%. Dalam siklus ini 3 anak sudah memasuki kriteria berkembang sangat baik dengan presentase $12,50 \%$. Menurut rekapitulasi data diatas, perolehan dari rata-rata diatas belum dapat untuk mencapai indikator keberhasilan yang diharapkan sebelumnya yaitu dengan kriteria berkembang sangat baik dan presentase $\geq 75 \%$. 


\section{Diskripsi Siklus II}

Tabel. 3 Rekapitulasi Data Hasil Observasi Siklus II

\begin{tabular}{lllll}
\hline Kriteria & \multicolumn{2}{l}{ Pertemuan 1 } & \multicolumn{2}{l}{ Pertemuan 2 } \\
\cline { 2 - 5 } & $\begin{array}{l}\text { Jml } \\
\text { Siswa }\end{array}$ & $\begin{array}{l}\text { Present } \\
\text { ase }\end{array}$ & $\begin{array}{l}\text { Jml } \\
\text { Siswa }\end{array}$ & $\begin{array}{l}\text { Prese } \\
\text { ntase }\end{array}$ \\
\hline $\begin{array}{l}\text { Perkembangan } \\
\text { Kognitif }\end{array}$ & 4 & 16,66 & 7 & 29,16 \\
Berkembang & & $\%$ & & $\%$ \\
Sangat Baik & & & & \\
\hline $\begin{array}{l}\text { Perkembangan } \\
\text { Kognitif }\end{array}$ & 11 & 45,83 & 12 & 50,00 \\
$\begin{array}{l}\text { Berkembang } \\
\text { Sesuai }\end{array}$ & & $\%$ & & $\%$ \\
Harapan & & & & \\
\hline $\begin{array}{l}\text { Perkembangan } \\
\text { Kognitif Mulai } \\
\text { Berkembang }\end{array}$ & 9 & 37,50 & 5 & 20,83 \\
$\%$ & $\%$ & & \\
\hline $\begin{array}{l}\text { Perkembangan } \\
\text { Kognitif }\end{array}$ & - & & - & \\
$\begin{array}{l}\text { Belum } \\
\text { Berkembang }\end{array}$ & & & & \\
\hline
\end{tabular}

Melihat data dari tabel diatas dapat diketahui bahwa tingkat perkembangan kognitif anak masih belum berkembang sudah tidak ada. Anak dengan kriteria mulai berkembang berkurang sebanyak 5 siswa yaitu dengan presentase sebesar 20,83\%. Anak dengan kriteria berkembang sesuai harapan meningkat sebanyak 12 siswa dengan presentase sebesar $50,00 \%$. Dalam siklus ini ada 7 anak sudah memasuki kriteria berkembang sangat baik dengan presentase sebesar $29,16 \%$.

\section{PEMBAHASAN}

Berdasarkan rekapitulasi data grafik di atas menunjukkan peningkatan perkembangan kognitif anak dari pra siklus ke siklus I kemudian meningkat lagi pada siklus II dengan jumlah presentase pada pra siklus yaitu sebesar $12,50 \%$ meningkat menjadi $50 \%$ pada siklus I, kemudian meningkat lagi menjadi $79,16 \%$ pada siklus II dengan kriteria berkembang sangat baik dan presentase $\geq 75 \%$. Hasil penelitian diatas diperkuat oleh teori piaget dalam Paul Suparno (2001:141), "Pengetahuan itu dibentuk sendiri oleh murid dalam berhadapan dengan lingkungan atau objek yang sedang dipelajarinya", Oleh karena itu, kegiatan murid dalam membentuk pengetahuanya sendiri menjadi hal yang sangat penting dalam sistem Piaget. Kemampuan pemecahan masalah anak usia dini dapat dikembangkan melalui berbagai upaya salah satunya dengan memberikan kesempatan atau peluang pada anak untuk mencari solusi dari permasalahan yang dihadapi dengan memberikan kebebasan kepada anak untuk bereksperimen dan bereksplorasi dengan benda-benda yang ada disekitar anak, lebih lanjut permasalahan yang diberikan kepada anak haruslah dihubungkan dengan dunia nyata dan berasal dari pengalamansehari-hari anak, agar anak lebih tertarrik untuk memecahkan masalah yang ditemuinya. Pembelajaran tersebut dapat membantu anak untuk lebih mengeksplorasi pengetahuanya dan mmampu merangsang anakuntuk berpikir memecahkan masalah. Manfaat lain dari pembelajaran ini adalah anak merasa tertantang untuk mempersiapkan diri terhadap pembelajaran berikutnya. Bagi anak usia dini, pendekatan saintifik merupakan salah satu bentuk pengenalan konsep kehidupan seharihari. Melalui kegiatan bermain, anak mampu mengeksplorasi pengetahuanya dan mendapatkan pengalaman dari kejadian yang pernah dialami. Para siswa kelompok B Pertiwi II Gagaksipat tahun pelajaran 2018/2019 sanagt antusias dalam mengikuti pembelajaran melalui pendekatan saintifik karena pembelajaran tersebut dapat menjawab rasa keingintahuan para siswa. 


\section{SIMPULAN}

1) Hasil penelitian menunjukkan bahwa penerapan pada pendekatan saintifik dapat meningkatkan perkembangan kognitif anak pada kelompok B TK Pertiwi II Gagaksipat Boyolali tahun pelajaran 2018/2019.

2) Terjadi Peningkatan presentase hasil belajar siswa pada siklus I perkembangan kognitif anak mengalami peningkatan sebanyak 12 anak dari 24 anak atau sebesar $50 \%$ berada pada kriteria berkembang sangat baik dan berkembang sesuai harapan. Sedangkan dalam siklus II, perkembangan kognitif anak mengalami peningkatan sebanyak 19 anak dari 24 anak atau sebesar $79,16 \%$ berada pada kriteria berkembang sangat baik dan berkembang sesuai harapan.

\section{DAFTAR RUJUKAN}

Arikunto, Suharsimi, Suhardjo \& Supardi. 2009. Penelitian Tindakan Kelas. Jakarta: PT. Bumi Aksara.

Saepudin, A. S. A. (2013). Pembelajaran Sains Pada Program Pendidikan Anak Usia Dini. Jurnal Teknodik, 213-226.

A.Machin. 2014. Implementasi Pendekatan Saintifik, Penanaman Karakter dan Konservasi pada Pembelajaran Materi Pertumbuhan. Jurnal Pendidikan IPA Indonesia. Vol.3, No.1.2014. Daryanto. 2014. Pendekatan Pembelajaran Saintifik Kurikulum 2013. Yogyakarta: Gava Media
Gunawan, I., \& Palupi, A. R. (2016). Taksonomi Bloom-revisi ranah kognitif: kerangka landasan untuk pembelajaran, pengajaran, dan penilaian. Premiere educandum: jurnal pendidikan dasar dan pembelajaran, 2(02).

Huliyah, Muhiyatul. HAKIKAT PENDIDIKAN ANAK USIA DINI. aș-șibyān : Jurnal Pendidikan Anak Usia Dini, Vol. 1 No 01 Januari. Tahun 2017.

Ibda, F. (2015). Perkembangan kognitif: teori jean piaget. Intelektualita, 3(1).

Kristanto, K., Khasanah, I., \& Karmila, M. (2011). Identifikasi model sekolah ramah anak (sra) jenjang satuan pendidikan anak usia dini se-kecamatan Semarang selatan. PAUDIA: JURNAL PENELITIAN DALAM BIDANG PENDIDIKAN ANAK USIA DINI, 1(1).

Dwy Rahayu, R. (2013). PENGARUH PENGGUNAAN VIDEO KARTUN MENCAMPUR WARNA TERHADAP KEMAMPUAN KOGNITIF PADA ANAK KELOMPOK B DI TK TERPADU ALHIDAYAH II DS. BAKUNG KEC. UDANAWU KAB. BLITAR. PAUD Teratai, 2(2). 